\title{
Prediction and analysis of annular pressure caused by temperature effect for HP/HT/HHS and water production gas wells in Sichuan Basin
}

\author{
Cao $\mathrm{Pu}^{1}$
}

Received: 27 August 2021 / Accepted: 25 November 2021 / Published online: 7 December 2021

(c) The Author(s) 2021

\begin{abstract}
For the "three-high" gas wells in Sichuan Basin which are often regulated for production rate and shut-in for maintenance, annular pressure by temperature effect is a kind of wellbore safety threat that cannot be ignored. In this work, the wellbore temperature and pressure calculation model of gas-liquid two-phase flow with non-hydrocarbon correction and the prediction model of annular pressure by temperature effect is developed. Moreover, the judgment chart of annular pressure type is established through a large number of simulation calculations with different gas production rates and water production rates. Example calculation shows that whether water production and non-hydrocarbon components are considered in the prediction model has a non-negligible influence on calculation results. The predicted annular pressure is compared with that obtained from the actual measurement showing a good agreement. Meanwhile, the judgment chart realizes the valid determination of annular pressure type for three "three-high" gas wells in Sichuan Basin. Influential factors analysis indicates that reducing the thermal expansion coefficient of annulus fluid, adding the hollow glass spheres or injecting highly compressible protective liquid into the annulus and installing compressible foam material on the inner wall of casing are effective methods to control the annular pressure by temperature effect. To reserve partial annulus space can effectively reduce the annular pressure by temperature effect. For most of "three-high" gas wells in Sichuan Basin, the optimum height of annulus air cavity is $100 \mathrm{~m}$.
\end{abstract}

Keywords Annular pressure $\cdot$ Temperature effect $\cdot$ Three-high gas well $\cdot$ Wellbore safety threat $\cdot$ Judgment chart

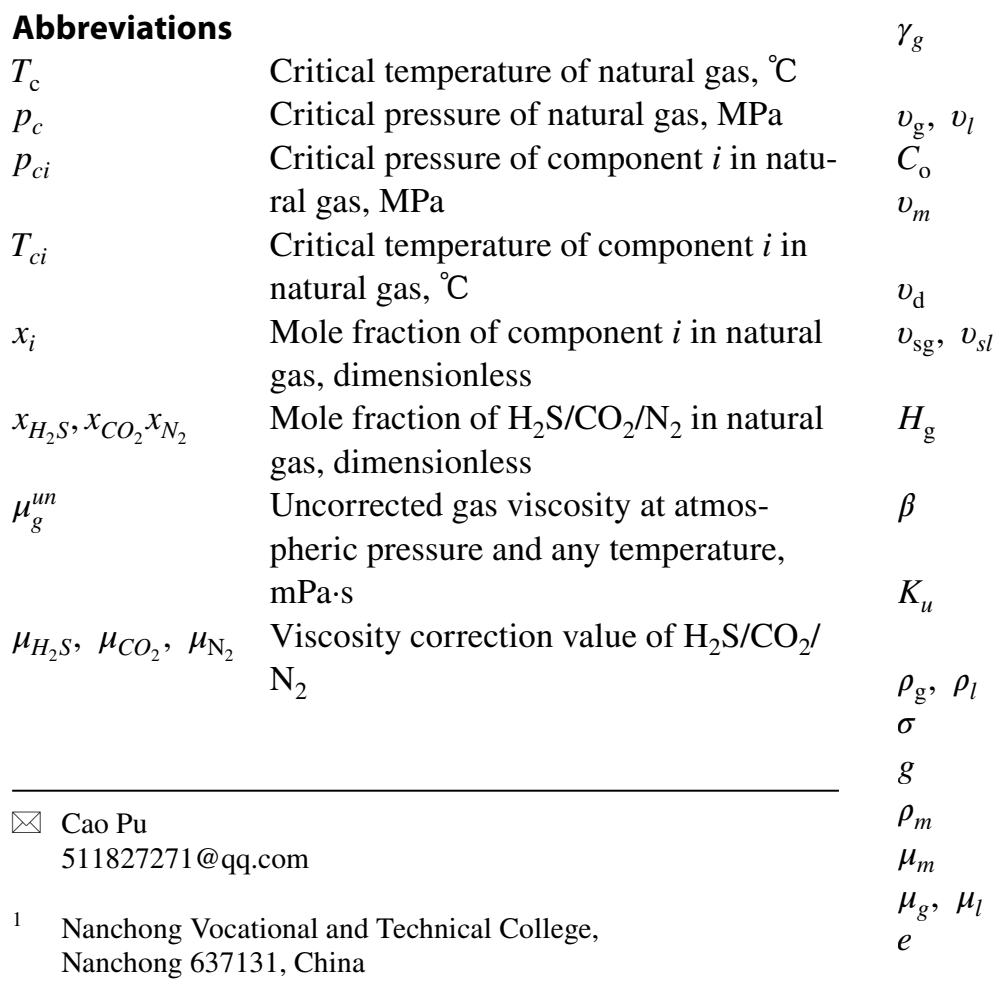

Relative density of natural gas, dimensionless

True gas/liquid velocity, $\mathrm{m} / \mathrm{s}$

Distribution coefficient, dimensionless Average velocity of two-phase mixture, $\mathrm{m} / \mathrm{s}$

Gas drift speed, m/s

Apparent velocity of the gas and the liquid, m/s

Gas holdup of wellbore cross section, dimensionless

Parameters related to section gas holdup and inundation velocity, dimensionless Critical Kutateladze number, dimensionless Gas/liquid density, $\mathrm{kg} / \mathrm{m}^{3}$

Surface tension, N/m Gravitational acceleration, $\mathrm{m} / \mathrm{s}^{2}$ Density of two-phase mixture, $\mathrm{kg} / \mathrm{m}^{3}$ Viscosity of two-phase mixture, $\mathrm{mPa} \cdot \mathrm{s}$ Gas/liquid viscosity, $\mathrm{mPa} \cdot \mathrm{s}$ Absolute roughness of wellbore wall, $\mathrm{m}$ Nanchong 637131, China 


\begin{tabular}{|c|c|}
\hline$D$ & Diameter of wellbore,m \\
\hline$R e_{m}$ & Reynolds number, dimensionless \\
\hline$T_{f}$ & Fluid temperature in tubing, ${ }^{\circ} \mathrm{C}$ \\
\hline$q$ & Radial heat loss of fluid, $\mathrm{J} / \mathrm{s}$ \\
\hline$c_{p m}$ & $\begin{array}{l}\text { Specific heat at constant pressure of } \\
\text { fluid, } \mathrm{J} /\left(\mathrm{kg} \cdot{ }^{\circ} \mathrm{C}\right)\end{array}$ \\
\hline$\alpha_{H}$ & Joule-Thomson coefficient, ${ }^{\circ} \mathrm{C} / \mathrm{Pa}$ \\
\hline$r_{t o}$ & Tubing outer diameter, $\mathrm{m}$ \\
\hline$U_{t o}$ & $\begin{array}{l}\text { Total heat transfer coefficient, } \\
\mathrm{W} \cdot\left(\mathrm{m} \cdot{ }^{\circ} \mathrm{C}\right)^{-1}\end{array}$ \\
\hline$k_{e}$ & $\begin{array}{l}\text { Heat transfer coefficient of formation, } \\
\mathrm{W} \cdot\left(\mathrm{m} \cdot{ }^{\circ} \mathrm{C}\right)^{-1}\end{array}$ \\
\hline$G_{t}$ & $\begin{array}{l}\text { Mass flow rate of gas-liquid mixture, } \\
\mathrm{kg} / \mathrm{s}\end{array}$ \\
\hline$f\left(t_{D}\right)$ & $\begin{array}{l}\text { Dimensionless time function, } \\
\text { dimensionless }\end{array}$ \\
\hline$T_{e}$ & Formation temperature, ${ }^{\circ} \mathrm{C}$ \\
\hline$U_{t a}$ & $\begin{array}{l}\text { Annulus heat transfer coefficient, } \\
\mathrm{W} \cdot\left(\mathrm{m} \cdot{ }^{\circ} \mathrm{C}\right)^{-1}\end{array}$ \\
\hline$r_{h}$ & Wellbore radius, $\mathrm{m}$ \\
\hline$r_{\text {co }}$ & Casing outer diameter, $\mathrm{m}$ \\
\hline$h_{r}$ & $\begin{array}{l}\text { Radiative coefficient of annulus fluid, } \\
\mathrm{W} \cdot\left(\mathrm{m}^{2} \cdot{ }^{\circ} \mathrm{C}\right)^{-1}\end{array}$ \\
\hline$h_{c}$ & $\begin{array}{l}\text { Convective heat transfer coefficient of } \\
\text { annulus fluid, } \mathrm{W} \cdot\left(\mathrm{m}^{2} \cdot{ }^{\circ} \mathrm{C}\right)^{-1}\end{array}$ \\
\hline$K_{c e m}$ & $\begin{array}{l}\text { Heat transfer coefficient of cement ring, } \\
\mathrm{W} \cdot\left(\mathrm{m} \cdot{ }^{\circ} \mathrm{C}\right)^{-1}\end{array}$ \\
\hline$T_{\mathrm{h}}$ & $\begin{array}{l}\text { Temperature at the outer edge of cement } \\
\text { ring, }{ }^{\circ} \mathrm{C}\end{array}$ \\
\hline$T_{a}$ & $\begin{array}{l}\text { Temperature in production casing annu- } \\
\text { lus, }{ }^{\circ} \mathrm{C}\end{array}$ \\
\hline$\Delta p_{a}$ & Annulus pressure change value, $\mathrm{MPa}$ \\
\hline$\alpha_{l}$ & $\begin{array}{l}\text { Thermal expansion coefficient of annu- } \\
\text { lus fluid, }{ }^{\circ} \mathrm{C}^{-1}\end{array}$ \\
\hline$k_{T}$ & $\begin{array}{l}\text { Isothermal compressibility of annulus } \\
\text { fluid, } \mathrm{MPa}^{-1}\end{array}$ \\
\hline$\Delta T_{a}$ & Annulus temperature change value, ${ }^{\circ} \mathrm{C}$ \\
\hline$\Delta V_{a}$ & Annulus volume change value, $\mathrm{m}^{3}$ \\
\hline$V_{a}$ & Annulus volume, $\mathrm{m}^{3}$ \\
\hline$C_{t o t}$ & $\begin{array}{l}\text { Deformation coefficient of tubing and } \\
\text { casing, } 10^{-6} \mathrm{MPa}^{-1}\end{array}$ \\
\hline$\alpha_{s}$ & $\begin{array}{l}\text { Thermal expansion coefficient of tubing } \\
\text { and casing, } 10^{-6 \circ} \mathrm{C}^{-1}\end{array}$ \\
\hline$p_{1}, p_{2}$ & $\begin{array}{l}\text { Pressure before and after annular pres- } \\
\text { sure change, MPa }\end{array}$ \\
\hline$z_{1}, z_{2}$ & $\begin{array}{l}\text { Gas deviation coefficient before and } \\
\text { after annular pressure change, MPa }\end{array}$ \\
\hline$T_{a 1}, T_{a 2}$ & $\begin{array}{l}\text { Annulus temperature before and after } \\
\text { annular pressure change, }{ }^{\circ} \mathrm{C}\end{array}$ \\
\hline$V_{g 1}, V_{g 2}$ & $\begin{array}{l}\text { Upper air cavity volume before and after } \\
\text { annular pressure change, } \mathrm{m}^{3}\end{array}$ \\
\hline
\end{tabular}

\section{Introduction}

There are some marine carbonate gas fields in Sichuan Basin, including Puguang gas field, Yuanba gas field, Moxi gas field and so on. These gas fields are characterized by high pressure (HP), high temperature (HT), high hydrogen sulfide (HHS) content, complex geological condition, water production and densely populated area. They are typical "three-high" gas fields (Li 2013; Xue et al. 2013; Su et al. 2014). Production casing annular pressure appears in almost all production wells during the exploitation of these gas fields. According to the cause of production casing annular pressure, it can be divided into annular pressure caused by temperature effect and annular pressure caused by leakage effect. The annular pressure by temperature effect is called normal annular buildup pressure, while the annular pressure by leakage effect is called abnormal annular buildup pressure (Zhu et al. 2012a, b; Zhu et al. 2012a, b; Valadez et al. 2014). Generally speaking, abnormal annular buildup pressure is the biggest threat to production safety, but for these "three-high" gas wells in Sichuan Basin which are often regulated for production rate and shut-in for maintenance, annular pressure by temperature effect is also a kind of wellbore safety threat that cannot be ignored (Singh et al. 2012; Julian et al. 2007). Frequent production regulation and shut-in for maintenance require continual pressure release to maintain pressure level, which increases safety operation risk and labor cost for these "three-high" gas wells. Therefore, it is very necessary to establish the prediction model of annular pressure by temperature effect and master its control factors. Once these control factors are acquired, corresponding parameters can be adjusted to reduce the threat of annular pressure to wellbore safety (Huerta et al. 2009; Nishikawa et al. 1999; Al-Ansari et al. 2015).

Currently, some researchers have studied the annular pressure by temperature effect and reached some useful conclusions. Adams et al. (1994) and Halal et al. (1994) established the prediction model of annular pressure by temperature effect, respectively, and identified two mechanisms responsible for annular pressure by temperature effect (fluid thermal expansion and tubing buckling). Oudeman et al. (2006) used field test data to verify the theoretical model, and the results show that theoretical model has some overestimates in predicting annular pressure. Che zhengan et al. (2010) proposed the prediction model of annular pressure caused by fluid thermal expansion for HP/HT gas wells and carried out the example calculation. Zhang bo et al. (2016) derived the calculation model of wellbore temperature distribution in deepwater oil/gas wells based on the conservation of energy law and 
the heat transfer principle of multilayer cylinder walls, and proposed an iterative method to calculate the annular pressure. However, for these "three-high" gas wells in Sichuan Basin, their particularity is that gas production is accompanied by water production (the wellbore flow is gas-liquid two-phase flow); meanwhile, the produced natural gas contains hydrogen sulfide, carbon dioxide, nitrogen and other non-hydrocarbon components. Therefore, the two particularities need to be taken into account when establishing the prediction model of annular pressure by temperature effect (Oudeman et al. 1995).

In this paper, the wellbore temperature and pressure calculation model of gas-liquid two-phase flow with nonhydrocarbon correction is firstly established, and then, the prediction model of annular pressure by temperature effect is proposed in combination with two situations of whether the production casing annulus space is filled with protective liquid. Through example calculation and parameter sensitivity analysis, the law of normal annular buildup pressure is obtained and the corresponding control measures of annular pressure by temperature effect are put forward. Moreover, the judgment chart of the type of production casing annular pressure is established through a large number of simulation calculations with different gas production rates and water production rates. Meanwhile, the judgment chart is applied in actual field to realize the judgment of annular pressure type for several gas wells. The above works in this paper can provide reference for annular pressure management and risk control for similar "three-high" gas fields.

\section{Wellbore temperature and pressure prediction model}

Most of the "three-high" gas wells in Sichuan Basin produce water, ranging from several cubic meters to dozens of cubic meters. Meanwhile, the produced natural gas contains hydrogen sulfide (3.8-15.1\%), carbon dioxide (4.8-8.64\%), nitrogen (1.04-3.56\%) and other non-hydrocarbon components. Therefore, the influence of gas-liquid two-phase flow and non-hydrocarbon components on calculation results should be considered when establishing the prediction model.

\section{Non-hydrocarbon correction}

The effect of non-hydrocarbon components such as hydrogen sulfide, carbon dioxide and nitrogen on gas physical parameters is mainly reflected by the calibration of gas deviation coefficient and gas viscosity.

For the calibration of gas deviation coefficient, the following model is adopted (Guo et al. 2000).
$T_{c}=T_{m}-C_{w a}$

$p_{c}=T_{c} \sum_{i=1}^{n}\left(x_{i} p_{\mathrm{c} i}\right) /\left[T_{\mathrm{c}}+x_{\mathrm{H}_{2} S}\left(1-x_{\mathrm{H}_{2} S}\right) C_{w a}\right]$

$T_{m}=\sum_{i=1}^{n}\left(x_{i} T_{\mathrm{c} i}\right)$

$C_{w a}=\frac{1}{14.5038}\left\{120\left[\left(x_{\mathrm{CO}_{2}}+x_{\mathrm{H}_{2} S}\right)^{0.9}-\left(x_{\mathrm{CO}_{2}}+x_{\mathrm{H}_{2} S}\right)^{1.6}\right]+15\left(x_{\mathrm{H}_{2} \mathrm{~S}}^{0.5}-x_{\mathrm{H}_{2} S}^{4}\right)\right\}$

The standing calibration model is used to correct the gas viscosity.

$\mu_{g}=\mu_{g}^{u n}+\mu_{H_{2} S}+\mu_{C O_{2}}+\mu_{N_{2}}$

$\mu_{H_{2} S}=x_{H_{2} S}\left[0.00849 \lg \left(\gamma_{\mathrm{g}}\right)+0.00373\right]$

$\mu_{\mathrm{CO}_{2}}=x_{\mathrm{CO}_{2}}\left[0.00908 \lg \left(\gamma_{\mathrm{g}}\right)+0.00624\right]$

$\mu_{\mathrm{N}_{2}}=x_{\mathrm{N}_{2}}\left[0.00848 \lg \left(\gamma_{g}\right)+0.00959\right]$

\section{Wellbore gas-liquid drift model}

In the gas-liquid two-phase wellbore flow, the gas surpasses the liquid because of the difference in density of the two phases, which is generally referred to as the gas-liquid slip. Therefore, a drift model considering gas-liquid slip is established to calculate the gas holdup and fluid physical parameters at any depth of wellbore.

In the gas-liquid two-phase wellbore flow, the true gas velocity can be expressed as:

$v_{\mathrm{g}}=C_{\mathrm{o}} v_{\mathrm{m}}+v_{\mathrm{d}}$

The average velocity of the two-phase mixture is the sum of the apparent velocities of the gas and the liquid:

$v_{m}=v_{\mathrm{sg}}+v_{s l}=H_{g} v_{g}+\left(1-H_{g}\right) v_{l}$

For the distribution coefficient $C_{o}$, its expression is:

$C_{o}=\frac{A}{1+(A-1) \gamma^{2}}, \gamma=(\beta-B) /(1-B), 0 \leq \gamma \leq 1$

For the gas drift speed $v_{d}$, its expression is:

$v_{d}=\left(1-H_{\mathrm{g}} C_{\mathrm{o}}\right) C_{\mathrm{o}} K_{u} v_{c} /\left(H_{g} C_{o} \sqrt{\rho_{g} / \rho_{l}}+1-H_{\mathrm{g}} C_{\mathrm{o}}\right)$ 
$v_{c}=\left[\frac{\sigma g\left(\rho_{l}-\rho_{\mathrm{g}}\right)}{\rho_{1}^{2}}\right]^{1 / 4}$

After determining the distribution coefficient and the gas drift speed, the gas holdup of wellbore cross section and the physical parameters of two-phase mixture can be determined:

$\rho_{m}=\rho_{l}\left(1-H_{\mathrm{g}}\right)+\rho_{g} H_{g}$

$\mu_{m}=\mu_{l}^{\left(1-H_{g}\right)} \mu_{g}^{H_{g}}$

\section{Wellbore pressure model}

The pressure gradient equation of gas-liquid two-phase wellbore flow can be obtained from the conservation of mass and momentum laws:

$\frac{d p}{d z}=-\rho_{m} g \sin \theta-f_{m} \frac{\rho_{m} v_{m}^{2}}{2 D}-\rho_{\mathrm{m}} v_{m} \frac{d v_{\mathrm{m}}}{d z}$

The friction coefficient $f_{\mathrm{m}}$ is calculated by the Jain method:

$\frac{1}{\sqrt{f_{\mathrm{m}}}}=1.14-2 \lg \left(\frac{e}{D}+\frac{21.25}{\operatorname{Re}_{\mathrm{m}}^{0.9}}\right), \operatorname{Re}_{\mathrm{m}}=\frac{\rho_{\mathrm{m}} v_{\mathrm{m}} D}{\mu_{\mathrm{m}}}$

\section{Wellbore temperature model}

The wellbore temperature gradient equation can be acquired from the conservation of energy and the first law of thermodynamics:

$\frac{d T_{f}}{d z}=\frac{d q}{c_{p m} d z}-\frac{g \sin \theta}{c_{p m}}-\frac{v}{c_{p m}} \frac{d v}{d z}+\alpha_{\mathrm{H}} \frac{d p}{d z}$

The heat loss of fluid from tubing to formation is:

$\frac{d q}{d z}=-\frac{2 \pi r_{\mathrm{to}} U_{t o} k_{\mathrm{e}}}{G_{t}\left[r_{t o} U_{t o} f\left(t_{\mathrm{D}}\right)+k_{e}\right]}\left(T_{f}-T_{e}\right)$

Combined with Eqs. 18 and 19, the wellbore temperature gradient equation can be converted to:

$\frac{d T_{f}}{d z}=-\frac{\left(T_{f}-T_{e}\right)}{A}-\frac{g \sin \theta}{c_{\mathrm{pm}}}-\frac{v}{c_{\mathrm{pm}}} \frac{d v}{d z}+\alpha_{\mathrm{H}} \frac{d p}{d z}$

where

$A=\frac{c_{\mathrm{pm}} G_{t}}{2 \pi}\left(\frac{r_{t o} U_{t o} f\left(t_{\mathrm{D}}\right)+k_{e}}{r_{t o} U_{t o} k_{e}}\right)$
After the temperature inside tubing is determined, the temperature at the outer edge of the cementing ring can be calculated:

$T_{\mathrm{h}}=\frac{T_{f} f\left(t_{\mathrm{D}}\right)+k_{e} T_{\mathrm{e}} / r_{t o} U_{\mathrm{to}}}{f\left(t_{\mathrm{D}}\right)+k_{\mathrm{e}} / r_{t o} U_{t o}}$

According to the heat transfer principle of series thermal resistance, the temperature in the production casing annulus can be obtained:

$T_{a}=T_{f}-\frac{U_{t o}}{U_{t a}}\left(T_{\mathrm{f}}-T_{\mathrm{h}}\right)$

$U_{t o}=\left[\frac{1}{h_{r}+h_{\mathrm{c}}}+\frac{r_{t o} \ln \frac{r_{h}}{r_{c o}}}{K_{c e m}}\right]^{-1}, U_{\mathrm{ta}}=\left[\frac{1}{h_{r}+h_{c}}\right]^{-1}$

\section{Annular pressure prediction model by temperature effect}

In most cases, the filling state of protective fluid in production casing annulus can be divided into two scenarios: One is full filling, and the other is partial filling. Therefore, the annular pressure prediction model needs to be established for the two cases, respectively.

\section{Full filling scenario}

For the case of production casing annulus is full filled with protective fluid, when the annular temperature increases the thermal expansion of annulus fluid occurs immediately. The annular pressure will go up since annulus fluid cannot expand freely. Meanwhile, as the annular pressure rises, the tubing and the casing are compressed and the annulus volume increases, which in turn reduces the annular pressure. Therefore, the annular pressure finally reaches a stable pressure value under the interaction of the two factors. The annular pressure change can be expressed as:

$\Delta p_{a}=\frac{\alpha_{1}}{k_{T}} \Delta T_{a}-\frac{1}{k_{T} V_{a}} \Delta V_{a}$

where

$\frac{\Delta V_{a}}{V_{a}}=C_{t o t} \Delta p_{a}+\alpha_{\mathrm{s}} \Delta T_{a}$

Substituting Eq. 26 into Eq. 25: 
$\Delta p_{a}=\left(1+\frac{C_{t o t}}{k_{T}}\right)^{-1} \cdot \frac{\left(\alpha_{l}-\alpha_{s}\right)}{k_{T}} \Delta T_{a}$

\section{Partial filling scenario}

For the case of production casing annulus is partial filled with protective fluid, when the annular temperature increases the thermal expansion of annulus fluid occurs immediately and the volume of the upper gas cavity of the production casing annulus decreases. The annular pressure will goes up with the increase in the annulus temperature and the decrease in the upper air cavity volume. The annular pressure change can be obtained from the gas state equation:

$\Delta p_{\mathrm{a}}=p_{2}-p_{1}=\left(\frac{z_{2} T_{a 2}}{z_{1} T_{a 1}} \frac{V_{g 2}}{V_{\mathrm{g} 1}}-1\right) p_{1}$

The volume of the upper air cavity after reduction is:

$V_{g 2}=V_{g 1}-\left(V_{a}-V_{g 1}\right) \cdot \alpha_{l}$

For this scenario, there is also a kind of special circumstances. When the thermal expansion of annulus fluid causes the production casing annulus to change from the partial filling state to the full filling state, the annular pressure change should be determined by combining calculation methods of the above two scenarios.

\section{Applications}

\section{Case study}

In this section, a "three-high" gas well of MX121H in Sichuan Basin is selected as a test case. The pertinent basic parameters of the well are given in Table 1 . The above two prediction models are used to calculate the annular temperature and the annular pressure by temperature effect for the well at a production rate of $46.2 \times 10^{4} \mathrm{~m}^{3} / \mathrm{d}$.

The wellbore temperature distribution and the predicted annular pressure by temperature effect are shown in Fig. 1 and Table 2, respectively. As we can observe, as production proceeds, the produced high temperature fluid causes wellbore radial heat transfer, which leads to a significant rise in annular temperature. The average annular temperature increases from $85.8^{\circ} \mathrm{C}$ before production to $121.6^{\circ} \mathrm{C}$ after production. The rising annular temperature eventually causes a significant increase in annular pressure, reaching $32.2 \mathrm{MPa}$. The differential pressure at the packer is equal to the annular pressure plus the annulus fluid column pressure minus the flowing pressure at the packer, reaching $60 \mathrm{MPa}$. Furthermore, the downhole flowing pressure will gradually decrease and the differential pressure at the packer will continue to increase with production. Notably, the pressure rating of the used packer for most "three-high" gas wells in Sichuan Basin
Table 1 Basic parameters of the gas well of MX121H

\begin{tabular}{|c|c|}
\hline Parameters & Value \\
\hline Packer depth/m & 6755 \\
\hline Downhole temperature $/{ }^{\circ} \mathrm{C}$ & 154.7 \\
\hline Downhole pressure/MPa & 62.3 \\
\hline Tubing diameter/mm & 89 \\
\hline Density of annulus protective fluid $/\left(\mathrm{g} \cdot \mathrm{cm}^{-3}\right)$ & 1.3 \\
\hline Thermal expansion coefficient of tubing and casing $/\left(10^{-6 o} \mathrm{C}^{-1}\right)$ & 18 \\
\hline Deformation coefficient of tubing and casing $/\left(10^{-6} \mathrm{MPa}^{-1}\right)$ & 57.8 \\
\hline Thermal expansion coefficient of annulus fluid $/\left(10^{-6 \circ} \mathrm{C}^{-1}\right)$ & 457 \\
\hline Isothermal compressibility of annulus fluid $/\left(10^{-6} \mathrm{MPa}^{-1}\right)$ & 450 \\
\hline Height of annulus air cavity/m & 0 \\
\hline Outer diameter of casing/mm & 193.7 \\
\hline Inner diameter of casing/mm & 168.3 \\
\hline Gas production rate $/\left(10^{4} \mathrm{~m}^{3} \cdot \mathrm{d}^{-1}\right)$ & 46.2 \\
\hline Water production rate $/\left(\mathrm{m}^{3} \cdot \mathrm{d}^{-1}\right)$ & 8 \\
\hline Geothermal gradient $/\left(\mathrm{K} \cdot \mathrm{m}^{-1}\right)$ & 0.0204 \\
\hline Heat transfer coefficient of formation/[W.(m. $\left.\left.{ }^{\circ} \mathrm{C}\right)^{-1}\right]$ & 1.73 \\
\hline Heat transfer coefficient of cement ring/[W.(m. $\left.\left.{ }^{\circ} \mathrm{C}\right)^{-1}\right]$ & 0.98 \\
\hline Total heat transfer coefficient/[W. $\left.\left(\mathrm{m} \cdot{ }^{\circ} \mathrm{C}\right)^{-1}\right]$ & 11.36 \\
\hline Convective heat transfer coefficient of annulus fluid/[W $\left.\cdot\left(\mathrm{m}^{2} \cdot{ }^{\circ} \mathrm{C}\right)^{-1}\right]$ & 9200 \\
\hline Initial annular pressure/MPa & 0.1 \\
\hline
\end{tabular}




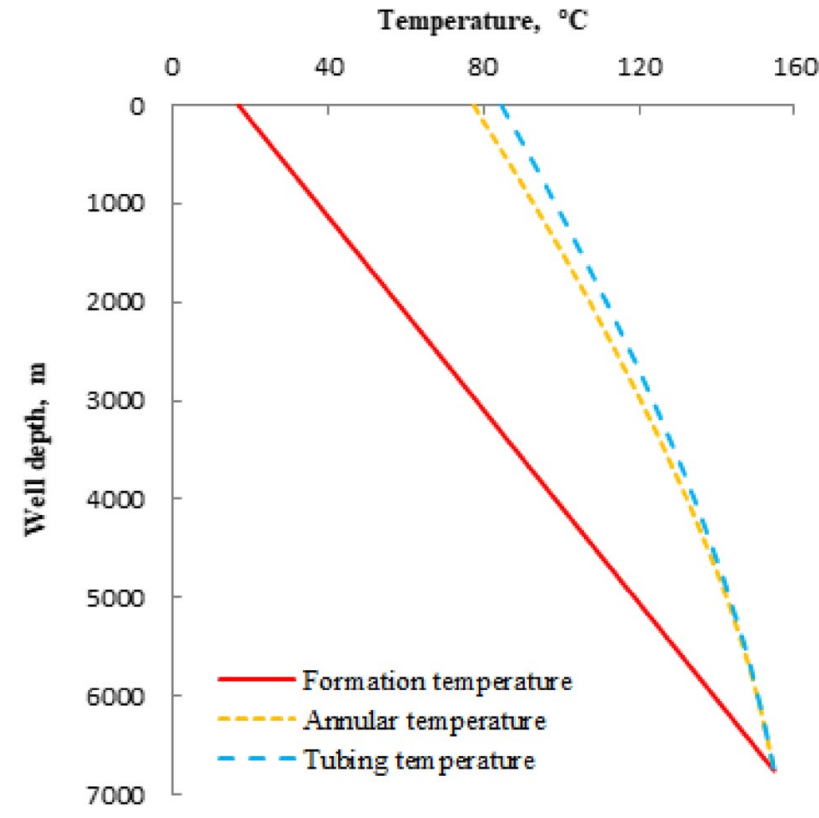

Fig.1 Temperature distribution along the wellbore

Table 2 Comparison between the predicted and actual measured annular pressures

\begin{tabular}{lllll}
\hline Position & $\begin{array}{l}\text { Average } \\
\text { temperature } \\
\text { before pro- } \\
\text { duction } /{ }^{\circ} \mathrm{C}\end{array}$ & $\begin{array}{l}\text { Average } \\
\text { temperature } \\
\text { after pro- } \\
\text { duction } /{ }^{\circ} \mathrm{C}\end{array}$ & $\begin{array}{l}\text { Predicted } \\
\text { annular } \\
\text { pressure/ } \\
\mathrm{MPa}\end{array}$ & $\begin{array}{l}\text { Actual meas- } \\
\text { ured annular } \\
\text { pressure / } \\
\mathrm{MPa}\end{array}$ \\
\hline $\begin{array}{c}\text { Production } \\
\text { casing } \\
\text { annulus }\end{array}$ & 85.8 & 121.6 & 32.2 & 31.7 \\
\hline
\end{tabular}

is $70 \mathrm{MPa}$. Therefore, the annular pressure by temperature effect will make the wellbore face the greater safety risk.

Generally, annular pressure by temperature effect can be eliminated by pressure release. However, for the "three-high" gas wells in Sichuan Basin which are often regulated for production rate and shut-in for maintenance, frequent pressure release to maintain pressure level increases safety operation risk and labor cost. Therefore, it is very necessary to take control measures to reduce the annular pressure by temperature effect.

Meanwhile, from Table 2 shown, the predicted annular pressure is very close to the actual measured annular pressure, and the error is only $1.5 \%$. The above observation indicates that the prediction model developed in this paper has high accuracy in calculating annular pressure by temperature effect.

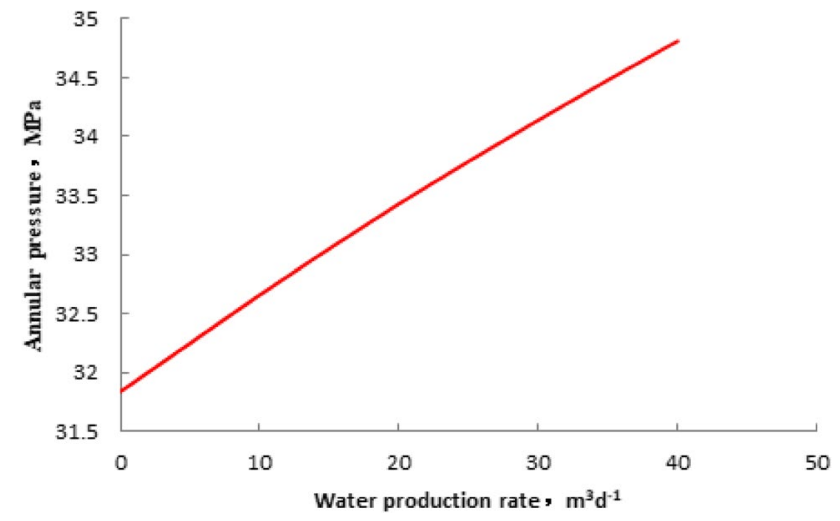

Fig.2 Annular pressures for different water production rates

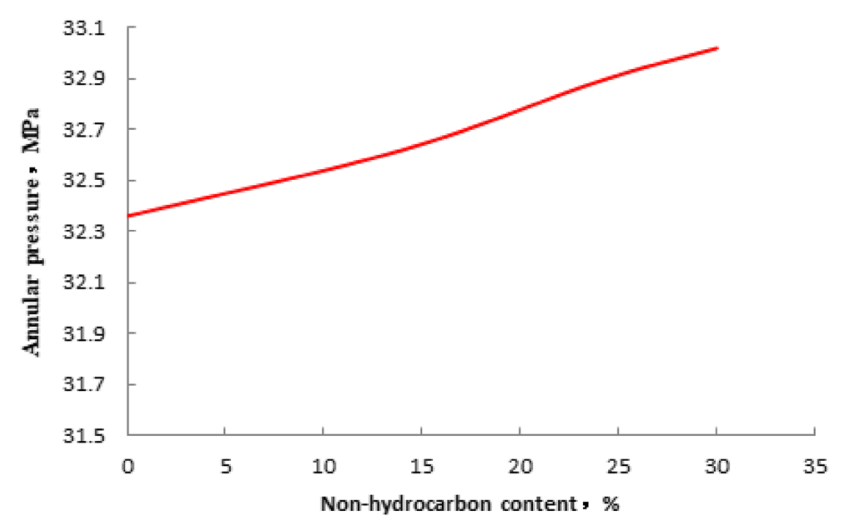

Fig.3 Annular pressures for different non-hydrocarbon contents

\section{Influential factors analysis}

\section{Water production rate and non-hydrocarbon content}

The influence of water production rate and the content of non-hydrocarbon components on annular pressure by temperature effect is illustrated in Figs. 2 and 3, respectively. As we can observe, the greater the water production rate, the higher the wellbore and annular temperature, ultimately resulting in the higher annular pressure. The water production rate has an obvious effect on the annular pressure. Meanwhile, as shown in Fig. 3, the influence law of non-hydrocarbon content on annular pressure is the same as that of water production rate. However, the impact degree of non-hydrocarbon content on annular pressure is less than that of water production rate. To sum up, water production rate and non-hydrocarbon content have a nonnegligible influence on annular pressure by temperature effect. Taking no account of the two particularities in the prediction model will result in lower calculated value of annular pressure for the "three-high" gas wells in Sichuan Basin. 


\section{Thermal expansion coefficient of annulus fluid}

The annular pressures by temperature effect for different thermal expansion coefficients of annulus fluid are presented in Fig. 4. The figure clearly shows that the increase in the thermal expansion coefficient gives the higher annular pressure. This is mainly because that the greater the thermal expansion coefficient, the larger the expansion volume of annulus fluid under the same temperature difference, ultimately resulting in the higher pressure acting on the pipe wall. Therefore, reducing the thermal expansion coefficient of annulus fluid is an effective method to control the annular pressure by temperature effect.

\section{Isothermal compressibility of annulus fluid}

The annular pressures by temperature effect corresponding to different isothermal compressibilities of annulus fluid are calculated, respectively, and the results are illustrated in Fig. 5. As we can observe, the annular pressure gradually decreases with the increase in the isothermal compressibility of annulus fluid, but the decline rate gradually lowers with the increase in the isothermal compressibility. The main reason for this phenomenon is that the greater the isothermal compressibility, the larger the compression volume of annulus expanding fluid under the same pressure difference, ultimately resulting in the lower pressure acting on the pipe wall. Therefore, enhancing the isothermal compressibility of annular fluid is also an effective method to reduce the annular pressure by temperature effect. Adding the hollow glass spheres or injecting highly compressible protective liquid into the annulus are the specific field applications of this method.

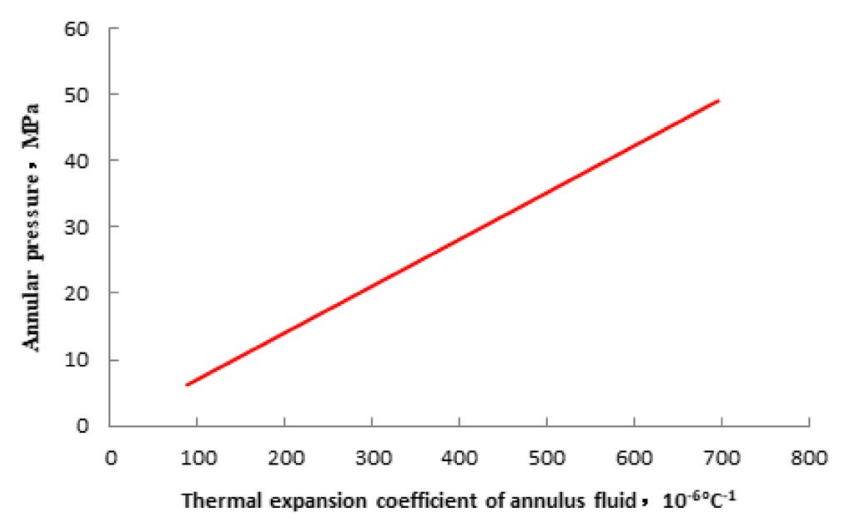

Fig.4 Annular pressures for different thermal expansion coefficients of annulus fluid

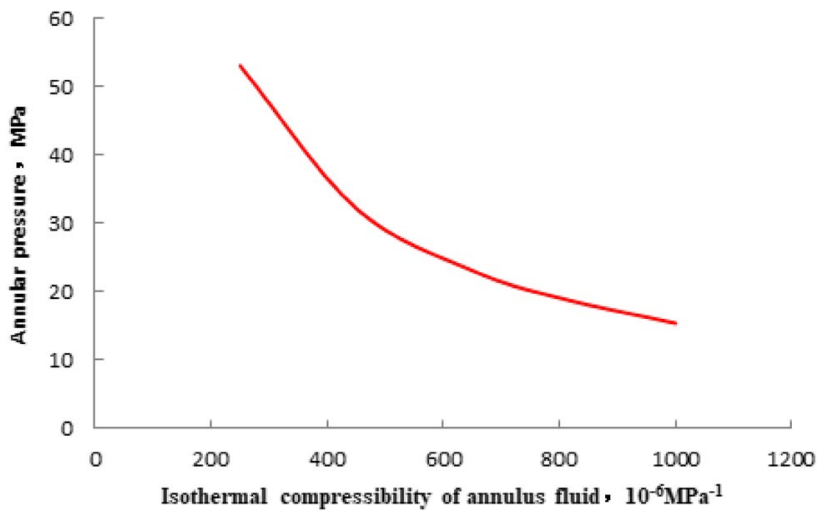

Fig.5 Annular pressures for different isothermal compressibilities of annulus fluid

\section{Deformation coefficient of tubing and casing}

The influence of deformation coefficient of tubing and casing on annular pressure by temperature effect is presented in Fig. 6. As shown in the figure, the annular pressure gradually decreases with the increase in the deformation coefficient of tubing and casing. It is obvious that the larger the deformation coefficient of tubing and casing, the greater the expanding annulus volume under the same pressure difference, ultimately resulting in the lower pressure acting on the pipe wall. Therefore, enhancing the deformation coefficient of tubing and casing is also an effective method to control the annular pressure by temperature effect. The installation of compressible foam material on the inner wall of casing is the specific field applications of this method.

\section{Height of annulus air cavity}

The annular pressures by temperature effect corresponding to the annulus air cavity heights of $0,10 \mathrm{~m}, 50 \mathrm{~m}, 80 \mathrm{~m}$, $100 \mathrm{~m}, 120 \mathrm{~m}$ and $150 \mathrm{~m}$ are calculated, respectively, and the

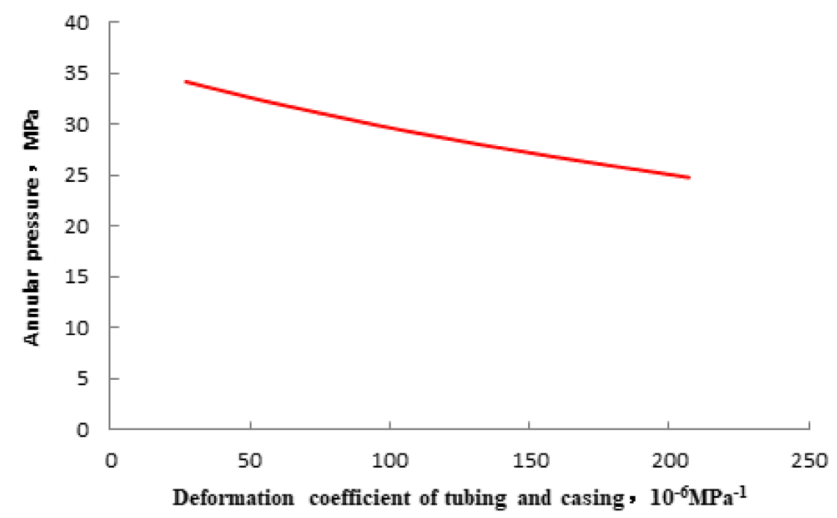

Fig.6 Annular pressures for different deformation coefficients of tubing and casing 
results are illustrated in Fig. 7. As shown in the figure, the annular pressure gradually decreases with the increase in the annulus air cavity height. However, when the height of annulus air cavity reaches a critical value, the annular pressure drops very slowly. Obviously, an increase in the height of annulus air cavity means that there is more annulus volume reserved for protective fluid expansion, finally resulting in the lower pressure acting on the pipe wall. Moreover, when the reserved annulus volume is larger than the expansion of annulus fluid at the allocated production rate, the decline rate of annular pressure will be very small with the increase in the annulus air cavity height. Meanwhile, increasing the height of annulus air cavity also brings a negative effect of increasing the risk of annulus casing corrosion. Therefore, there is an optimum height of annulus air cavity at a allocated production rate. In practice, when these "three-high" gas wells are put into production, the annulus needs not to be filled with protective fluid; that is, partial annulus space can be reserved, which can effectively reduce the annular pressure by temperature effect. For most of "three-high" gas wells in Sichuan Basin with allocated production rate of $50 \times 10^{4} \mathrm{~m}^{3} / \mathrm{d}$, the optimum height of annulus air cavity is $100 \mathrm{~m}$.

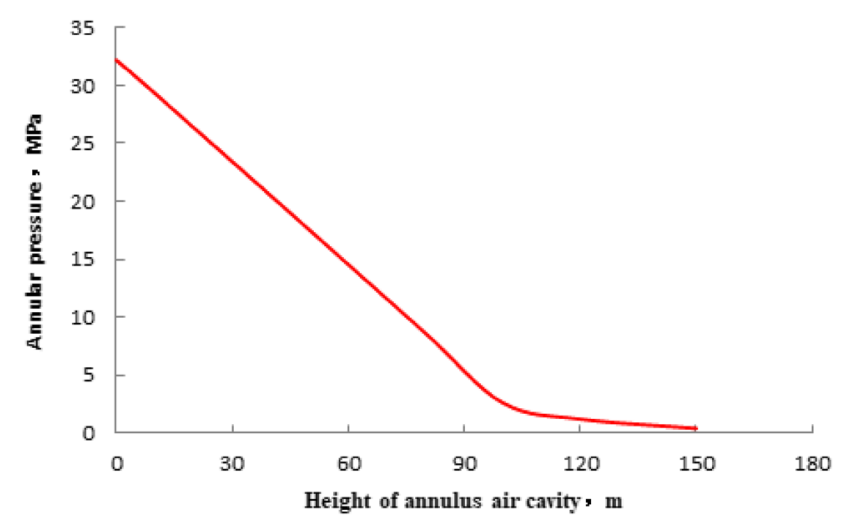

Fig.7 Annular pressures for different heights of annulus air cavity

\section{Judgment chart of the type of production casing annular pressure}

\section{Chart establishment}

Another work done in this paper is to use the above two prediction models to calculate the annular pressures by temperature effect under different gas production rates and water production rates, and these calculated results are further used to establish a judgment chart, which can realize the rapid judgment of the type of production casing annular pressure. The specific judgment chart is presented in Fig. 8 . From this figure shown, the judgment chart is divided into two regions, including the region of normal annular buildup pressure and another region of abnormal annular buildup pressure. The type of production casing annular pressure can be determined by judging which region the actual measured annular pressure is in. Notably, the judgment chart in Fig. 8 is calculated based on the geological parameters and wellbore parameters of a block in Sichuan Basin. If the judgment chart is applied to other blocks or others fields, the corresponding geological parameters and wellbore parameters used in prediction models should be updated. The specific judgment methods are as follows:

(1) No pressure release has occurred in the production casing annulus.

The actual measured annular pressure is compared with the predicted annular pressure by temperature effect under the corresponding gas production rate and water production rate. If the actual measured value is lower than the predicted value, the type of annular pressure belongs to normal annular buildup pressure. If the actual measured value is higher than the predicted value, it indicates that there is leakage in the production casing annulus and the type of annular pressure belongs to abnormal annular buildup pressure.
Fig.8 Judgment chart of the type of tubing and casing annular pressure

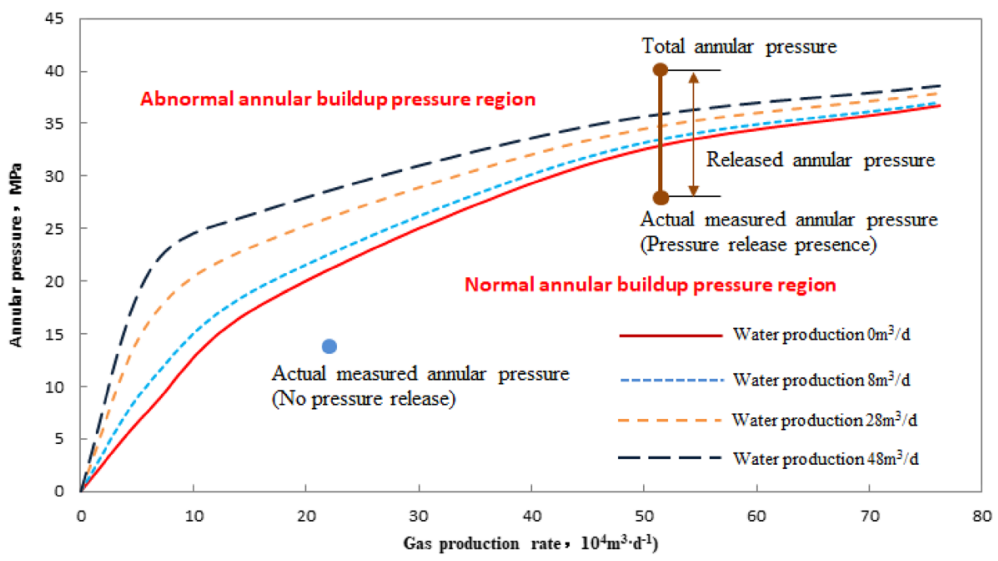


(2) Pressure release has occurred in the production casing annulus.

Firstly the previous released annular pressure is added to the actual measured annular pressure to obtain the total annular pressure. Then the total annular pressure is compared with the predicted annular pressure by temperature effect under the corresponding gas production rate and water production rate. If the total annular pressure is lower than the predicted value, the type of annular pressure belongs to normal annular buildup pressure. If the total annular pressure is higher than the predicted value, it indicates that there is leakage in the production casing annulus and the type of annular pressure belongs to abnormal annular buildup pressure.

\section{Chart application}

The established judgment chart is then applied to three "three-high" gas wells in Sichuan Basin to determine the type of production casing annular pressure. Among them, the two wells of PG27-5H and YB1-2H are judged by production data before annular pressure release, while the well of MX2-1H is judged by production data after annular pressure release.

\section{(1) PG27-5H}

The production data of $\mathrm{PG} 27-5 \mathrm{H}$ is presented in Fig. 9. As shown in the figure, the maximum annular pressure before pressure release is $23.4 \mathrm{MPa}$, and the corresponding gas production rate is $45.3 \times 10^{4} \mathrm{~m}^{3} / \mathrm{d}$ and water production rate is $9 \mathrm{~m}^{3} / \mathrm{d}$. Combined with the judgment chart (Fig. 10) and the judgment method 1, it can be determined that the annular pressure in the production casing annulus of PG27-5H belongs to normal annular buildup pressure.

(2) YB1-2H

The production data of YB1-2H is shown in Fig. 11. As we can observe, the maximum annular pressure before pressure release is $37.7 \mathrm{MPa}$, and the corresponding gas production rate is $54.4 \times 10^{4} \mathrm{~m}^{3} / \mathrm{d}$ and water production rate is $8 \mathrm{~m}^{3} / \mathrm{d}$. Combined with the judgment chart (Fig. 12) and the judgment method

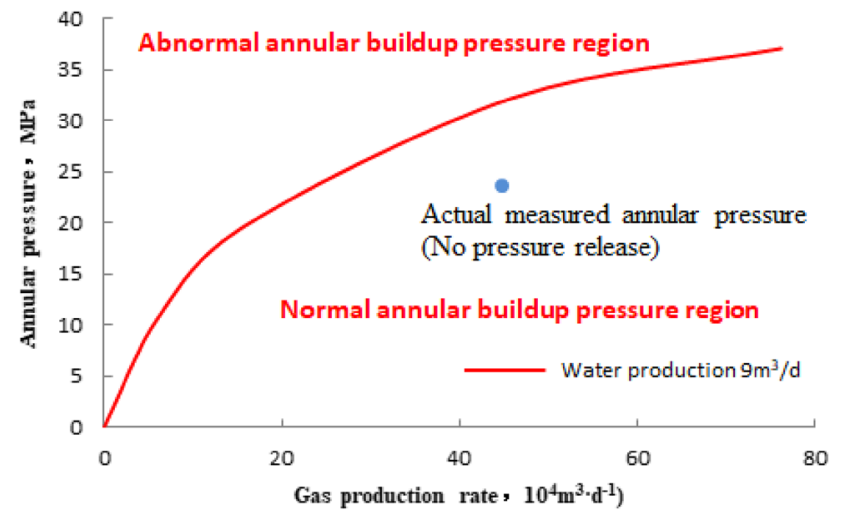

Fig.10 Judgment of annular pressure type for PG27-5H

1 , it can be determined that the annular pressure in the production casing annulus of YB1-2H belongs to abnormal annular buildup pressure.

(3) $\mathrm{MX} 121 \mathrm{H}$

The production data of MX121H is illustrated in Fig. 13. As shown in the figure, the annular pressure on May 5, 2020, after two pressure releases is 20.2 $\mathrm{MPa}$, and the corresponding gas production rate is $48.9 \times 10^{4} \mathrm{~m}^{3} / \mathrm{d}$ and water production rate is $10 \mathrm{~m}^{3} / \mathrm{d}$. Meanwhile, according to the pressure release record in the production process, the sum of previous two pressure releases is $18.3 \mathrm{MPa}$. Combined with the judgment chart (Fig. 14) and the judgment method 2, it can be determined that the annular pressure in the production casing annulus of MX121H belongs to abnormal annular buildup pressure.

\section{Validation of judgment results}

According to the analysis result of annulus gas samples for the above three wells (Table 3), it can be determined that the annulus gas sample of PG27-5H does not contain hydrogen sulfide, indicating that there is no leakage in the production casing annulus and the type of annular pressure belongs to normal annular buildup pressure. On the contrary, the annulus gas samples of YB1-2H and MX121H both contain
Fig.9 Production data of PG27$5 \mathrm{H}$

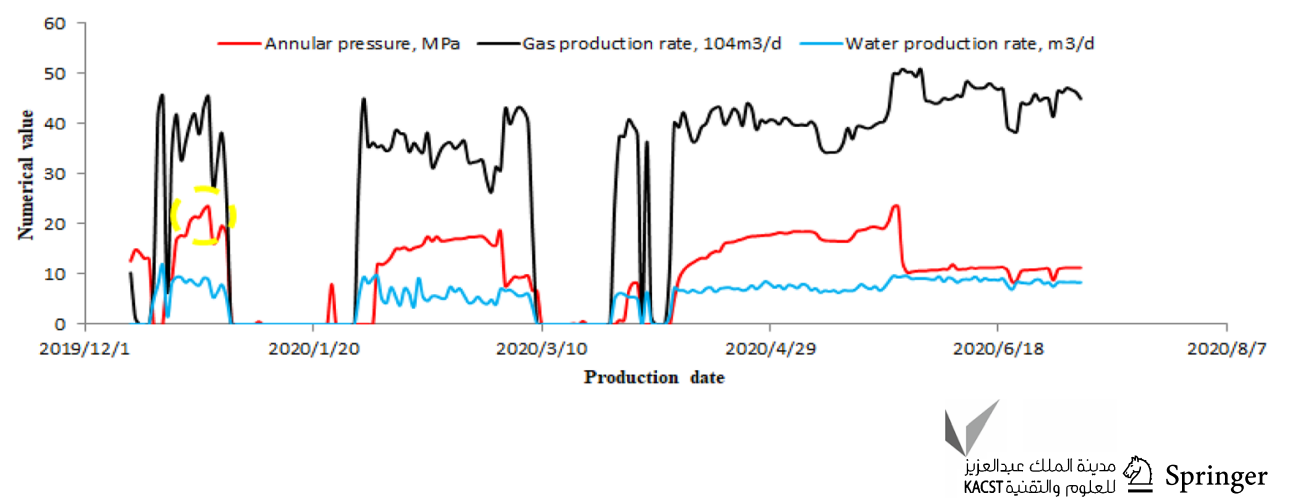


Fig.11 Production data of YB1-2H

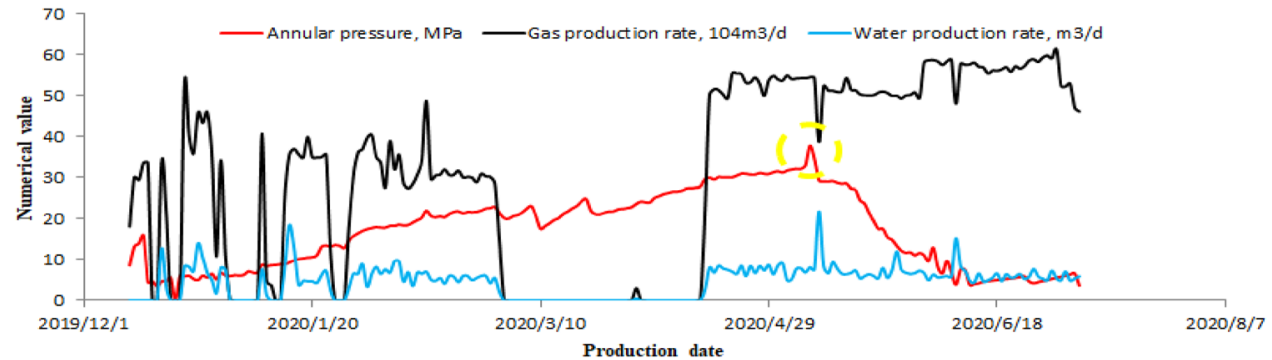

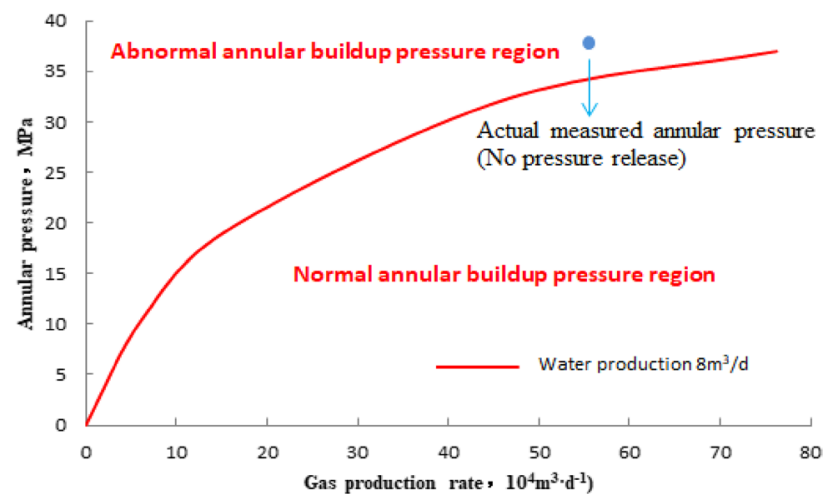

Fig.12 Judgment of annular pressure type for YB1-2H

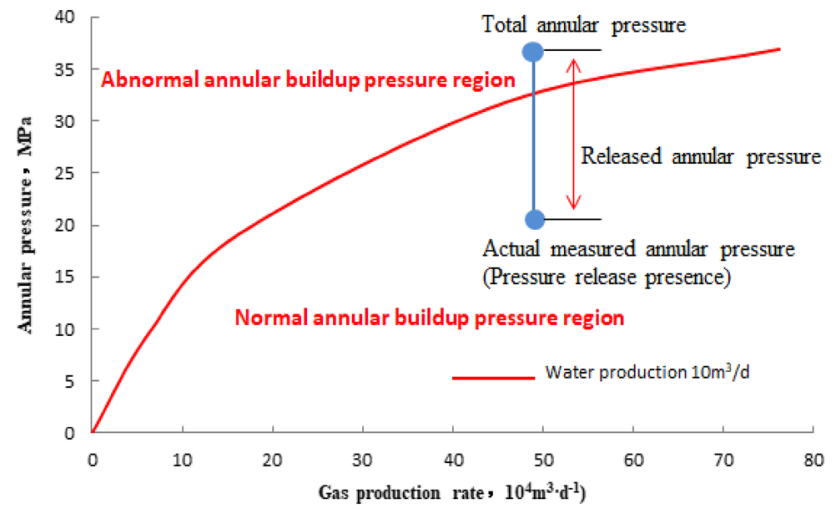

Fig.14 Judgment of annular pressure type for MX121H hydrogen sulfide, indicating that there is leakage in the production casing annulus and the type of annular pressure belongs to abnormal annular buildup pressure. Therefore, the previous judgment of annular pressure type for the above three wells is validated by the analysis results of annulus gas samples.

\section{Conclusions}

(1) The wellbore temperature and pressure calculation model of gas-liquid two-phase flow with non-hydrocarbon correction and the prediction model of annular pressure by temperature effect is developed in this work. Example calculation shows that whether water production and non-hydrocarbon components are considered in the prediction model has a non-negligible influence on calculation results of annular pressure by temperature effect. Comparison between the predicted annular pressure and the actual measured annular pressure reveals that the established prediction model has potential practical application in calculating annular pressure by temperature effect.

(2) Through influential factors analysis, the influence law of control parameters on annular pressure by temperature effect is acquired and the corresponding control measures are put forward. Reducing the thermal expansion coefficient of annulus fluid, adding the hollow glass spheres or injecting highly compressible protective liquid into the annulus and installing compressible foam material on the inner wall of casing are effective and practical methods to control the annular pressure by temperature effect.
Fig.13 Production data of MX121H

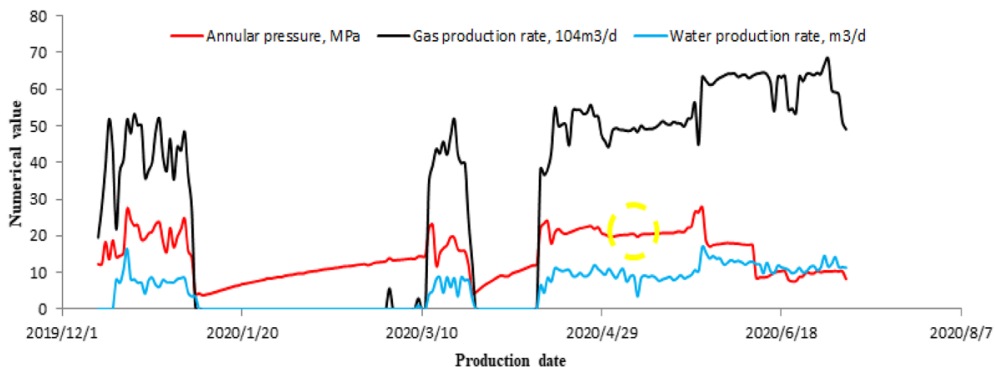


Table 3 Analysis result of annulus gas samples for PG27-5H, YB1-2H and MX121H

\begin{tabular}{llllllll}
\hline Well & $\mathrm{N}_{2} / \%$ & $\mathrm{CO}_{2} / \%$ & $\mathrm{H}_{2} \mathrm{~S} / \%$ & $\mathrm{CH}_{4} / \%$ & $\mathrm{C}_{2} \mathrm{H}_{6} / \%$ & Relative density & Actual density \\
\hline PG27-5H & 0.245 & 0 & 0 & 87.191 & 0.034 & 0.5498 & 0.6712 \\
YB1-2H & 0.234 & 5.732 & 7.784 & 85.280 & 0.036 & 0.6378 & 0.7958 \\
MX121H & 0.382 & 4.156 & 9.346 & 86.142 & 0.285 & 0.6453 & 0.7645 \\
\hline
\end{tabular}

(3) In practice, the annulus needs not to be filled with protective fluid; that is, partial annulus space can be reserved, which can effectively reduce the annular pressure by temperature effect. For most of "three-high" gas wells in Sichuan Basin with allocated production rate of $50 \times 10^{4} \mathrm{~m}^{3} / \mathrm{d}$, the optimum height of annulus air cavity is $100 \mathrm{~m}$.

(4) The judgment chart of annular pressure type is established through a large number of simulation calculations with different gas production rates and water production rates. The chart is applied to three "three-high" gas wells in Sichuan Basin to realize the judgment of annular pressure type. Meanwhile, the analysis result of annulus gas samples verifies the validity of the judgment chart.

Funding The author is grateful for financial support by the Nanchong Science and Technology Program (No. 20YFZJ0033).

Open Access This article is licensed under a Creative Commons Attribution 4.0 International License, which permits use, sharing, adaptation, distribution and reproduction in any medium or format, as long as you give appropriate credit to the original author(s) and the source, provide a link to the Creative Commons licence, and indicate if changes were made. The images or other third party material in this article are included in the article's Creative Commons licence, unless indicated otherwise in a credit line to the material. If material is not included in the article's Creative Commons licence and your intended use is not permitted by statutory regulation or exceeds the permitted use, you will need to obtain permission directly from the copyright holder. To view a copy of this licence, visit http://creativecommons.org/licenses/by/4.0/.

\section{References}

Adams AJ, MacEachran A (1994) Impact on casing design of thermal expansion of fluids in confined annuli. SPE Drill Complet 9(3):210-216

Al-Ansari A A, Al-Refai I M, Al-Beshri M H, et al. (2015) Thermal activated resin to avoid pressure build-up in casing-casing annulus(CCA) [R]. SPE175425

Che ZA, Zhang Z, Shi TH et al (2010) Mechanism of annular fluid thermal expansion pressure in HTHP sour gas wells. Nat Gas Ind 30(2):88-90
Guo XQ, Yan W, Chen S et al (2000) Comparison of methods for calculating compressibility factor of natural gas at elevated high pressure. J Univ Pet China(Edition of Natural Science) 24(6):36-38

Halal AS, Mitchell RF (1994) Casing design for trapped annular pressure build-up. SPE Drill Complet 9(2):107-114

Huerta NJ, Checkai DA, Bryant SL (2009) Utilizing sustained casing pressure analog to provide parameters to study $\mathrm{CO}_{2}$ leakage rates along a wellbore[R]. SPE126700

Julian JY, King GE, Cismoski DA, et al (2007) Downhole leak determination using fiber-optic distributed-temperature surveys at Prudhoe Bay, Alaska[R]. SPE107070

Li LG (2013) Progress in and developing orientation of technologies for the recovery and production of high-sulfur gas reservoirs in China. Nat Gas Ind 33(1):18-24

Nishikawa S (1999) Mechanisms of gas migration after cement placement and control of sustained casing pressure. Louisiana State University, Louisiana

Oudeman P, Bacarezza LJ (1995) Field trial results of annular pressure behavior in a HP/HT well. SPE Drill Complet 10(2):84-88

Oudeman P, Kerem M (2006) Transient behavior of annular pressure build-up in HP/HT wells. SPE Drill Complet 21(4):234-241

Singh S K, Subekti H, Al-Asmakh M, et al (2012) An integrated approach to well integrity evaluation via reliability assessment of well integrity tools and methods: results from Dukhan field, Qatar[R]. SPE156052

Su B, Long G, Xu XQ et al (2014) Safe completion and production technologies of a gas well with ultra depth, high temperature, high pressure and high $\mathrm{H}_{2} \mathrm{~S}$ content: a case from the Yuanba Gas Field in the Sichuan Basin. Nat Gas Ind 34(7):60-64

Valadez TR, Hasan AR, Mannan S et al (2014) Assessing wellbore integrity in sustained casing pressure annulus. SPE Drill Complet 29(1):131-138

Xue LN, Zhou XH, Yan YC et al (2013) Material selection of the production casing in high-temperature sour gas reservoirs in the Changxing Formation, Yuanba Gas Field, northeastern Sichuan Basin. Nat Gas Ind 33(1):85-89

Zhang B, Guan ZC, Sheng YN et al (2016) Impact of wellbore fluid properties on trapped annular pressure in deepwater wells. Pet Explor Dev 43(5):1-7

Zhu HJ, Lin YH, Zeng DZ et al (2012a) Calculation analysis of sustained casing pressure in gas wells. Pet Sci 9(1):66-74

Zhu HJ, Lin YH, Zeng DZ et al (2012b) Mechanism and prediction analysis of sustained casing pressure in "A" annulus of $\mathrm{CO}_{2}$ injection well. J Petrol Sci Eng 92-93:1-10

Publisher's Note Springer Nature remains neutral with regard to jurisdictional claims in published maps and institutional affiliations. 